\title{
Activity patterns of two species of Nesomys (Muridae: Nesomyinae) in a Madagascar rain forest
}

\author{
JAMES M. RYAN*, G. KEN GREIGHTON ${ }^{\dagger}$ and LOUISE H. EMMONS ${ }^{\dagger}$ \\ * Biology Department, Hobart and William Smith Colleges, Geneva, New York 14456, \\ USA \\ $\dagger$ Division of Mammals, National Museum of Natural History, Smithsonian Institution, \\ Washington, DC 20560, USA
}

KEY WORDS: Nesomys, rodents, Madagascar, ecology, activity.

The Nesomyinae is a subfamily of muroid rodents endemic to Madagascar (Carleton \& Musser 1984). Ten species in seven genera are now recognized (Corbet \& Hill 1986, Petter 1972, 1975), but it is likely that the Nesomyinae contains more species than previously recognized (Carleton \& Schmidt 1990). The genus Nesomys contains a single species, $N$. rufus, with three recognized subspecies: N. r. rufus, N. r. audeberti, and N. r. lambertoni (Petter 1975). Specimens of $N$. r. lambertoni are known only from the type locality in western Madagascar near Maintirano. The other two subspecies inhabit eastern and northern rain forests, with $N$. r. audeberti found in lowland rain forest (from sea level to $1000 \mathrm{~m}$ ) and $N$. r. rufus restricted to montane rain forests $(900-2300 \mathrm{~m}$; Carleton \& Schmidt 1990).

During July 1987 we found that both $N$. r. rufus and $N$. r. audeberti co-occurred at 900-1000 m elevation at Parc Nationale de Ranomafana. The syntopic distributions and discrete characters observed near Ranomafana for the two forms suggest their genetic isolation. Taxonomic studies are underway to clarify the status of the two forms. We consider that these two currently recognized subspecies are species, and hereafter we refer to the two forms as $N$. rufus and $N$. audeberti. We undertook a preliminary study of the ecology of Nesomys in an area of overlap between lowland and upland forms, with the aim of describing their activity patterns.

The study site is located on a ridge top at 900-1000 m elevation in Parc Nationale de Ranomafana (21 $15^{\prime} \mathrm{S} ; 47^{\circ} 26^{\prime} \mathrm{E}$ ), near the village of Ranomafana, Province de Fianarantsoa. This area is classified as eastern montane rain 
forest (Jenkins 1987) and receives an average annual rainfall of between 2000 and $3000 \mathrm{~mm}$. The site is on steep mountain slopes. The vegetation is characterized by a $20-25 \mathrm{~m}$ canopy forest and is transitional between lowland rain forest and high elevation sclerophyllous forests $(1300-2300 \mathrm{~m})$. Epıphytes, lianas, mosses, orchids, and lichens are very abundant, the herb layer is well developed, and ground litter is extensive with a dense root mat.

When captured in the field, the two forms of Nesomys are easily separable by differences in colour of the venter, body weight and hindfoot length. Nesomys rufus is the smaller form. The mean body weight of $19 \mathrm{~N}$. rufus males was $176.6 \mathrm{gm}$ (SE $=3.44$ ), which is significantly different from that of eight $N$. audeberti males (224.3 gm; SE = 6.86; Mann-Whitney $U$ test, $\mathrm{P}<0.001)$. Eleven female $N$. rufus averaged $146.2 \mathrm{gm}(\mathrm{SE}=3.7)$ in body weight compared with $205.7 \mathrm{gm}(\mathrm{SE}=$ 13.5) for seven female $N$. audeberti (Mann-Whitney U test, $\mathrm{P}<0.05$ ). Hindfoot lengths average $49 \mathrm{~mm}$ for $N$. rufus (both sexes) and are significantly smaller than those of $N$. audeberti $(54.6 \mathrm{~mm}$; Mann-Whitney U test, $\mathrm{P}<0.001)$. Nesomys audeberti has a white belly, while $N$. rufus has a rufous venter with white hairs confined to the chin and throat region and bright reddish hairs on the cheeks and flanks.

Radiotracking studies were conducted from June to August in 1987-1989, and spool and line tracking was done in 1989. Nesomys were captured with live-traps (National live traps) and were sexed, measured, weighed and ear-tagged with numbered fingerling tags. All animals were released at the capture site after handling. Four $N$, audeberti and four $N$. rufus ( 2 scrotal males and 2 adult females each) were selected for radiotelemetry, anaesthetized with an intramuscular injection of ketamine hydrochloride and fitted with $10 \mathrm{gm}$ motion-sensitive radio transmitters. Transmitters broadcast at two pulse rates depending on the activity of the animal. Animals were located by use of a hand-held threeelement-Yagi antenna.

We tracked two animals simultaneously on foot. Locations were triangulated from three compass bearings taken at three mapped trail marker numbers. Appropriate trails were selected to ensure the intersection of the three bearings. Bearings were taken nearly continuously (every 5-10 minutes) from pre-dawn until after dark. Animals were also tracked at various intervals during the night to verify that they remained in their dens until just after dawn. We located dens of radio-tagged animals by plotting the bearings on a trail map of the site. Minimum-convex-polygons were calculated for each animal following procedures outlined by Stickel (1954) and Mohr \& Strumpf (1966).

We used a spool-and-line tracking method modified from Anderson et al., (1988), Berry et al., (1987) and Miles et al., (1981) to locate den sites and to get a preliminary view of movement patterns and microhabitat use. We attached a spindle of no. 5 nylon reverse-wound thread (Culver Textiles Corp.) between the shoulder blades of the animal and followed the trail of thread that unwound as the animal moved through the forest. Spools contained approximately $175 \mathrm{~m}$ of thread that played out from the inside of the spindle so that there was no spool 


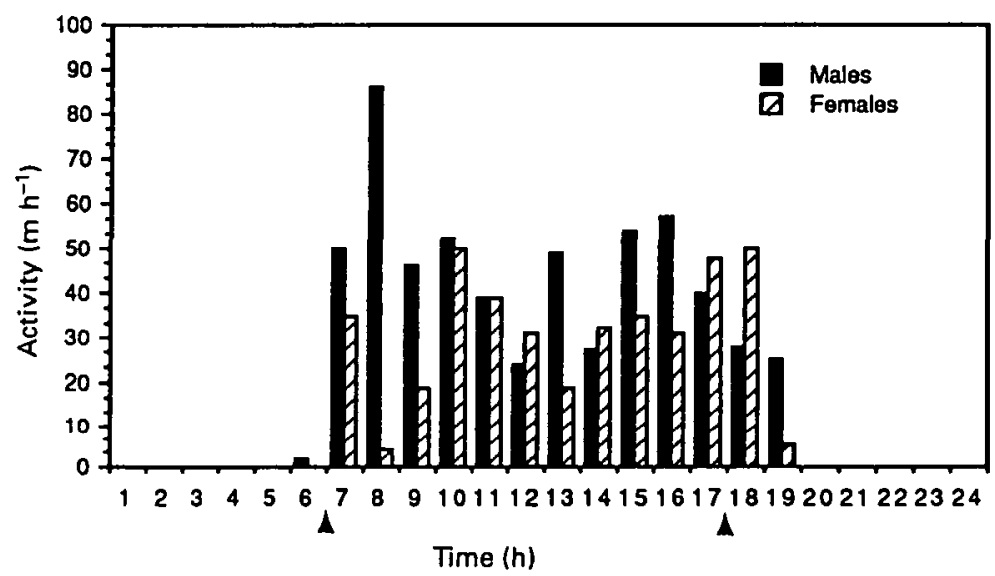

Figure 1. Daily activity patterns of two male and two female Nesomys rufus radiotracked in this study. Activity is expressed as the mean distance moved $\left(\mathrm{m} \mathrm{h}^{-1}\right)$ for each sex over the study period. Arrows indicate sunrise and sunset on a 24-hour time scale.

or housing. Spindles $(3 \mathrm{~cm} \times 1 \mathrm{~cm})$ were encased in 0.5 inch heat-shrink electrical tubing, which prevented the outer layers of thread from catching on vegetation and allowed the completed package to be glued directly to the animal's fur using Gel Super Glue. Completed spools weighed $1.96 \mathrm{~g}$ (SD = $0.04 \mathrm{~g}$; $\mathrm{N}=10$ ). On days spools were attached, we set traps at $1500 \mathrm{~h}$ and checked them at $1600 \mathrm{~h}$. Ten traps usually captured five Nesomys in one or two hours. Spools were quickly glued to unanaesthetized rats without inhibiting their respiration or locomotion. Spools generally remained attached to the animals for several days, even in heavy rains.

We followed thread trails the day after attachment. A trail ended either when the thread was broken and no trail could be found several metres away, when the spool was found, or when the thread ran out. Courses were plotted by taking compass bearings and estimating the length of thread $(\mathrm{m})$ between each direction change. Thread was removed from the forest floor during tracking to avoid confusion with trails of other animals. Plots of thread trails gave a precise topological map of each rat's activity. Thread trails often led to den sites because animals began heading to dens between 1730 and 1900 hours each night. Trails also showed details of habitat use and evidence of foraging (e.g. discarded or partially eaten fruits and seeds).

We defined activity as movement determined by changes into radio-transmitter pulse-rate and/or sequential radio-locations (Emmons 1988). An animal that was feeding or grooming (behaviourally active) would be determined to be inactive. Although sample sizes are small, the daily activity patterns of individuals of both species in this preliminary study were entirely diurnal and crepuscular. Male $N$. rufus tended to leave their dens earlier than females, usually at or just before sunrise ( 0630 hours; Figure 1). Males had three periods of increased activity (early morning, mid-day, and early afternoon). Females 


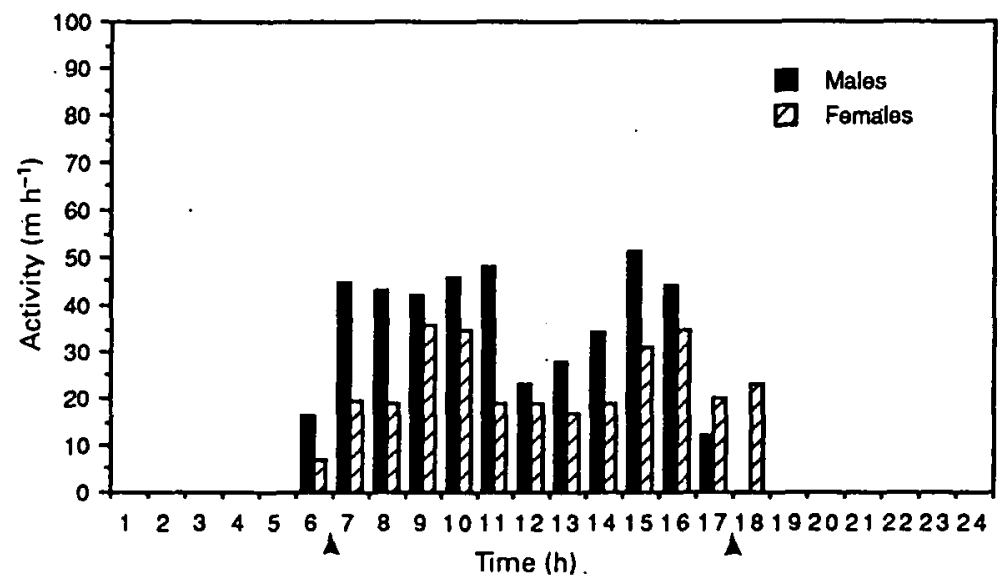

Figure 2. Daily activity patterns of two male and two female Nesomys audeberti radiotracked in this study. Activity is expressed as in Figure 1.

showed a trough in activity at mid-day and remained active until just before dusk (Figure 1). Male activity declined steadily from $1600 \mathrm{~h}$ to dusk. Activity of male and female $N$. audeberti was bimodal during our study period (Figure 2). Male and female $N$. audeberti left their dens just before sunrise. Both sexes were active in the morning and afternoon with a decline in activity at mid-day. All rats returned to their dens by $1900 \mathrm{~h}$ and remained there until the following morning. Male $N$. audeberti were more active than females for all but the last few hours of the day. Females tended to enter their dens later in the evening than males.

Male $N$. audeberti had home ranges of approximately 1.4 ha compared with only 0.5 ha for females. Male and female $N$. rufus had home range areas between 0.4 and 0.6 ha. Home-range area was not correlated with the number of radiolocations (Spearman's rank correlation, $\mathrm{r}=-0.166, \mathrm{P}>0.5$ ), indicating that variation in home range area was not caused by variation in the number of radiolocations.

Nesomys species did not use exclusive home ranges either intra- or intersexually. For example, male $N$. audeberti home ranges overlapped with both conspecific males and females. Live-trapping in the study area showed that each individual (of each species) shared its home-range with between two and eight other animals. For example, $N$. rufus female no. 325 shared a portion of its area with at least three other $N$. rufus (two males and one female). $N$. rufus male 318 overlapped with two male $N$. audeberti (308 and 311) and two female $N$. audeberti ( 376 and 326 ), as well as a conspecific male and female. There was similar intraand interspecific overlap in the home-ranges of male and female $N$. audeberti. Aggressive chases were rarely observed even though animals were occasionally observed within several metres of one another.

Average daily movements of individuals were fairly uniform. Distances represent underestimates because certain days were incompletely sampled (lost 
transmitter signals over various time spans). On average $N$. rufus travelled $400 \mathrm{~m}$ $(\mathrm{SD}=39 \mathrm{~m})$ day $^{-1}$. Females seemed to travel shorter distances per day and per hour than males. Nesomys audeberti of both sexes travelled $441 \pm 56 \mathrm{~m} \mathrm{day}^{-1}$ on average. We regularly observed solitary Nesomys travelling through vegetation on the forest floor. Typical undisturbed movement patterns were erratic and consisted of short bursts of running interspersed with slow walking or stationary periods. The movement rate was between 34 and $84 \mathrm{~m} \mathrm{~h}^{-1}$. These observations were consistent with data from thread tracking.

We tracked $N$. audeberti and two $N$. rufus with spool-and-line. These records gave precise movement patterns for an undetermined portion of the day. Thread trails showed that both species stayed close to downed logs, brush piles, and dense tangles of herbaceous vegetation when travelling. Movement was characterized by short $(<3 \mathrm{~m})$ zig-zags, with occasional straight runs of up to $10 \mathrm{~m}$ and numerous instances of doubling back on existing trails. Long straight runs tended to be across more open ground or when the animals crossed trails. All movements were terrestrial and only rarely did animals move along the top of fallen logs.

Each animal had several widely dispersed dens in its home-range. Five den sites (of three animals) were located with thread trails. Three of these dens were excavated later by hand. Typically, a den was located under brush piles or at the base of large trees with extensive root systems. Each den had several entrances that were approximately $7 \mathrm{~cm}$ in diameter and 2-3 m apart. All excavated dens were multichambered, with chambers located on two levels. Burrows leading into these chambers were always lined with freshly clipped grasses. Deeper chambers appeared to be used for sleeping, as they were lined with very finely shredded palm fronds (made by tearing thin strips from the dried petioles of dead fronds found lying on the ground). These palm trees (local name 'lafa'), grow to $8 \mathrm{~m}$ and are scattered throughout the study area. The bedding, $2-3 \mathrm{~cm}$ thick, was dry, and looked like pine-needles. It covered only the floor of the chamber and was arranged in a circular pattern approximately $20 \mathrm{~cm}$ in diameter. There were no food caches or latrines found in the three den systems excavated.

Dens were used primarily during the night. Several times animals went to den sites during mid-day, but this was unusual. Some rats used different dens on different nights, but most repeatedly returned to preferred sites. Although difficult to confirm, we believe that males and females (of a species) occasionally share dens. For example, on 3 August 1989, a N. rufus male (318) and female (321) had nearly identical radiolocations at sunset and afterwards.

Of three $N$. rufus marked in 1988, one was recaptured in 1989 only $10 \mathrm{~m}$ from its original capture site. Three male and six female $N$. audeberti were marked in 1988. Of those nine animals, only one male and one female were recaptured in 1989. Both animals were recaptured within $100 \mathrm{~m}$ of their 1988 capture sites. These data suggest that individuals of both species retain approximately the same home-range for more than one year.

The data presented here demonstrate that both species of Nesomys are 
exclusively diurnal. Diurnal murid rodents are rare in tropical rain forests (Emmons \& Feer 1988). Indeed, rain forests in Borneo lack diurnal murids entirely. In African rain forests, only species in the genera Hybomys and Lemniscomys are terrestrial and at least partially diurnal (Duplantier 1982, Kingdon 1974). Diurnality may be linked to lower energetic costs associated with high elevations or may be made possible by the deep litter/root layer which allows these rats easy access to escape routes. Alternatively, lack of competitors and/or fewer diurnal predators may have allowed Nesomys species to exploit the diurnal niche.

In addition to Nesomys, there are four other rodent species at our study site in Madagascar (Brachytarsomys albicauda Gunther 1875, Eliurus minor Major 1896b, E. myoxinus tanala Major 1896a, and Gymnuromys roberti Major 1896a, pers. obs., Carleton \& Schmidt 1990). At our study site the two species of Nesomys occur at high densities and are probably the most abundant rodents in this community. Brachytarsomys and both Eliurus species are nocturnal and exclusively arboreal. Gymnuromys roberti is nocturnal and terrestrial. Thus, the terrestrial niches are occupied by the two diurnal species of Nesomys and a single nocturnal species, G. roberti.

The eastern rain forests of Madagascar provide a unique opportunity to study a murid rodent community of manageable diversity and accessibility. However, because of the preliminary nature of this study, many questions remain unanswered. Long-term data are needed to document seasonal fluctuations in activity patterns for Nesomys species and to determine home-range size and use. Likewise, data are needed on the level of competition between the two species, the role predators play in regulating population density, duration of the pair bond, and the type of reproductive system exhibited by Nesomys species.

\section{ACKNOWLEDGEMENTS}

This research was supported by grants from the Smithsonian Institution and Hobart and William Smith Colleges. Dr P. Wright provided invaluable logistical support along with the use of her field site near Ranomafana. Thanks also go to A. Wright, P. Daniels, A. Yoder, E. Raholimavo, D. Quammen, and the people of Ambatolahy and Ranomafana. We are grateful to M. Carleton for reading earlier drafts of this manuscript.

\section{LITERATURE GITED}

ANDERSON, T. J. C., BERRY, A. J., AMOS, J. N. \& COOK, J. M. 1988. Spool-and-line tracking of the New Guinea spiny bandicoot, Echymipiera kalubu (Marsupialia, Perimelidae). Journal of Mammalogy 69:114-120.

BERRY, A. J., ANDERSON, T. J. C., AMOS, J. N. \& COOK, J. M. 1987. Spool-and-line tracking of giant rats in New Guinea. Joumal of Zoology, London 213:299-303.

CARLETON, M. D. \& MUSSER, G. G. 1984. Muroid rodents. Pp. 289-379 in Anderson, S. \& Jones, J. K. (eds). Orders and families of recent mammals of the world. John Wiley \& Sons, Inc., New York.

CARLETON, M. D. \& SCHMIDT, D. F. 1990. Systematic studies of Madagascar's endemic rodents (Muroidea:Nesomyinae): An annotated gazetteer of collecting tocalities of known forms. American Museum Novitales 2987:36pp. 
CORBET, G. B. \& HILL, J. E. 1986. A world list of mammalian species. (2nd edition). British Museum of Natural History, London. 234pp.

DUPLANTIER, J. M. 1982. Les rongeurs myomorphes forestiers du nord-est du Gabon: peuplements, ultilization de L'espace, et des ressources alimentaires, role dans la dispersion et la germination des graines. These 3eme Cycle, Universite de Sciences et Techniques du Languedoc.

EMMONS, L. H. 1988. A field study of ocelots (Felis pardalis) in Peru. Revue Ecologigue 43:133-157.

EMMONS, L. H. \& F. FEER. 1990. Neotropical rainforest mammals: a field guide. University of Chicago Press, Chicago. 281 pp.

JENKINS, M. D. 1987. Madagascar: an environmental profile. IUCN, Gland. 374pp.

KINGDON, J. 1974. East African mammals: an atlas of evolution in Africa, vol IIB Hares and rodents. University of Chicago Press, Chicago. 704pp.

MILES, M.A., DeSOUZA, A. A., \& POROA, M. M. 1981. Mammal tracking and nest location in Brazilian forest with an improved spool-and-line device. Journal of Zoology, London 195:331-347.

MOHR, C. O. \& STUMPF, W. A. 1966. Comparison of methods for calculating areas of animal activity. Joumal of Wildlife Management 30:293-304.

PETTER, F. 1972. The rodents of Madagascar: the seven genera of Malagasy rodents. Pp. $661-665$ in Battistini, R. \& Richard-Vindad, G. (eds). Biogeography and ecology in Madagascar. A. Junk, The Hague. 765pp.

PETTER, F. 1975. Family Cricetidae: subfamily Nesomyinae. P. 4 in Meester, J. \& Setzer, H. W. (eds). The mammals of Africa, an identification manual. Smithsonian Institution Press, Washington, DC.

STICKEL, L. F. 1954. A comparison of certain methods of measuring ranges of small mammals. Joumal of Mammalogy 35:1-15.

Accepted 2 July 1992 